
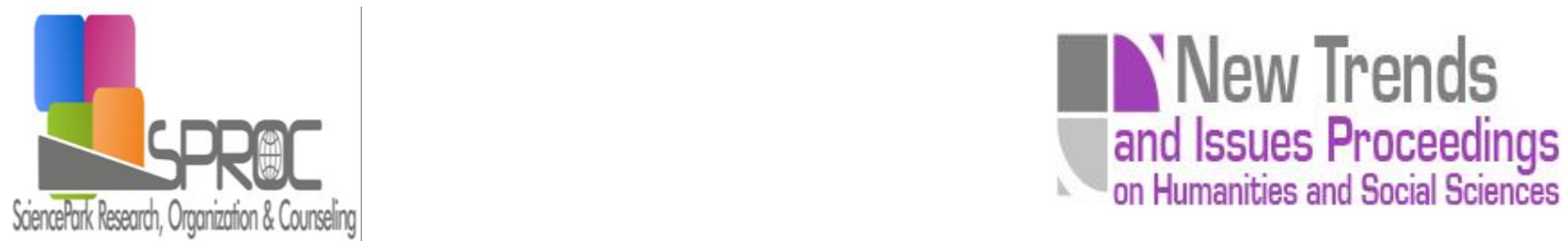

\title{
Waking up scientific vocations
}

\section{Eduardo Dopico ${ }^{\text {a* }}$}

Cristina Amstrong ${ }^{b}$

\section{Suggested Citation:}

Humanities and Social Sciences.

New Trends and Issues Proceedings on

Abstract 
1. Introduction 
2. Material and Methods 


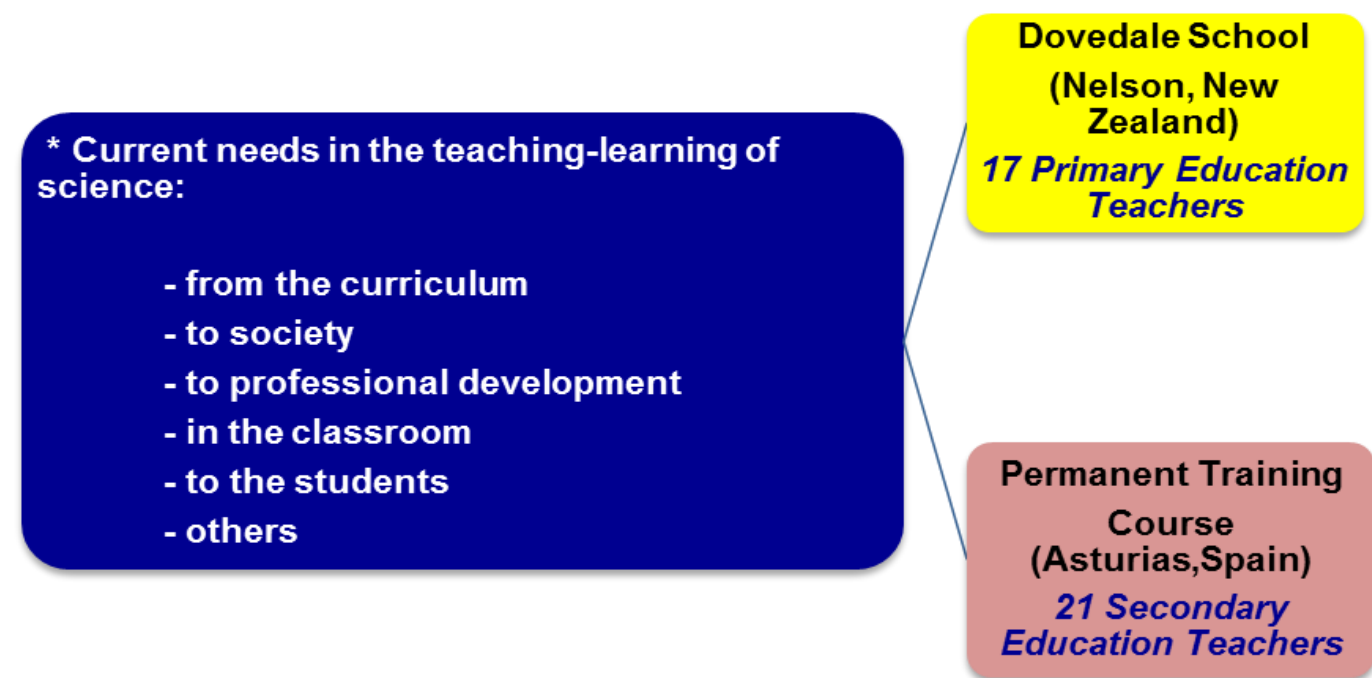

Figure 1. Teachers' perceptions on teaching science

\section{Results}

Table 2. Schools, activities and main results

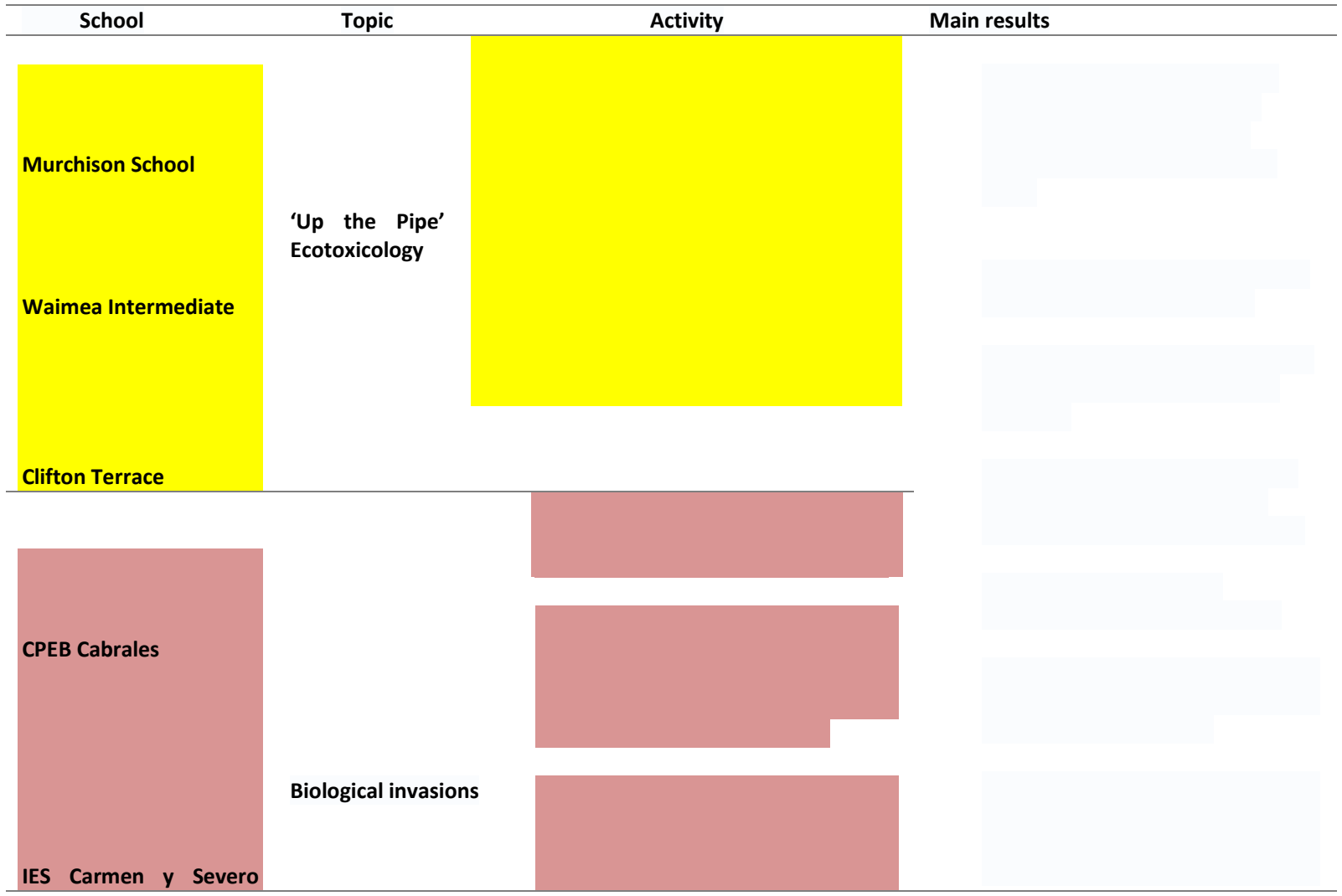




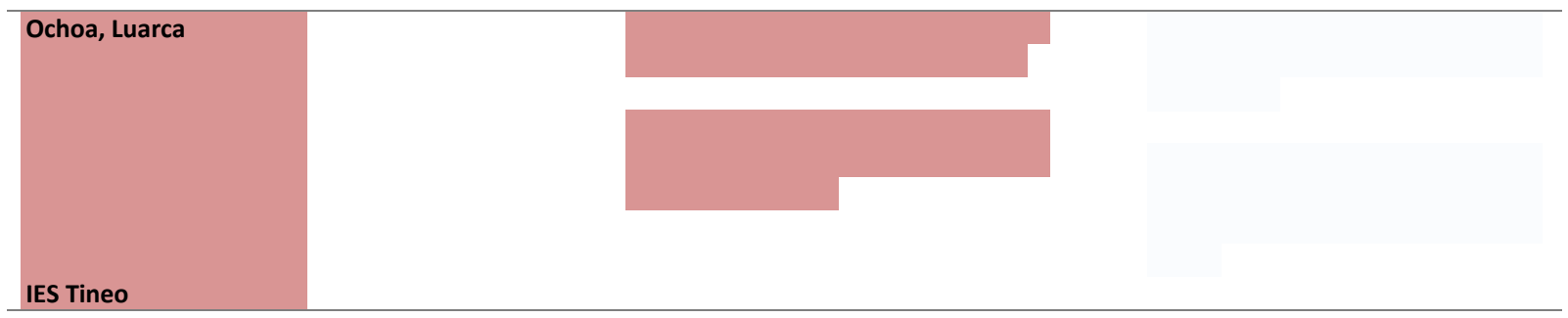

extend from schools the scientific literacy of citizens

open school doors for scientifics

try different teaching-learning methods

work in the classroom on an open curriculum

share basic principles on what it is nowadays to teach sciences

improve professional skills in science teaching

$\begin{array}{lllllll} & 0 \% & 20 \% & 40 \% & 60 \% & 80 \% & 100 \% \\ \text { - Permanent Training Course } & & \text { v Dovedale School } & & & \end{array}$

Figure 2. Improvements needed in the teaching of science, according to the interviewed teachers.

\section{Conclusions and Discussion}

Learning in Science Project

Primary Connections 


\section{References}

Science Education,

Pedagogy, Culture \& Society

Reading, writing and high-energy physics

Teachers

and Teaching

Research in Science Education

Economics of Education Review

International Journal of Science Education

Research in Science Education

European Journal of Education

Making links between science and learners world

Research in Science Education

Democracy and education. An introduction to the philosophy of education

Science literacy in primary schools and pre-schools

Australian Journal

of Teacher Education

Science Education in Europe: National Policies, Practices and Research

Science Education Policy-making Eleven emerging issues 
Revista Eureka sobre Enseñanza y Divulgación de las Ciencias

\section{Teaching Science}

The teaching of science in primary schools

Journal of vocational behavior 66

communications and technology 3

Handbook of research on educational

The democracy of knowledge

Journal of Research in Science Teaching

Cooperation in the 21st century

Education 3-13: International

Journal of Primary, Elementary and Early Years Education

International Journal of Science Education

Journal of Science Teacher Education

Education Research International

Creative teaching: Science in the early years and primary classroom: Science in the early years classroom

Learning in Science: The implications of children's science

Issues in Educational Research

Anales de Psicología

Journal of

Science Teacher Education

Rethinking the way we teach science: The interplay of content, pedagogy, and the nature of science

Education

Cambridge Journal of 